\title{
The expected and observed changes in the intake of three hays by sheep after shearing
}

\author{
By D. J. MINSON \\ Division of Tropical Pastures, CSIRO, Cooper Laboratory, Lawes, \\ Queensland, Australia \\ AND J. H. TERNOUTH* \\ Queensland Agricultural College, Lawes, Queensland, Australia \\ (Received 12 February 1970-Accepted 24 September 1970)
}

I. The effect of shearing Merino wethers on their voluntary intake of three hays of different digestibilities was studied in two experiments.

2. In Expt $I$, six groups of ten wethers in metabolism crates were given lucerne (a goodquality) hay, setaria (a medium-quality) hay and pangola (a poor-quality) hay ad lib., at an average room temperature of $25^{\circ}$. The sheep of one of the two groups given each hay were shorn at the beginning of the experimental period. For 4 weeks after shearing, the shorn sheep given lucerne hay had significantly lower intakes than the unshorn sheep. The intake of setaria was similar for the shorn and unshorn sheep, and the shorn sheep had significantly higher intakes of pangola than the unshorn sheep in the period 3-5 weeks after shearing.

3. Expt 2 was conducted similarly to Expt $I$, but using fifty-two wethers at an average room temperature of $13^{\circ}$ and using a different lucerne hay. The shorn sheep ate less lucerne than the unshorn sheep only in the Ist week after shearing. The shorn sheep had higher intakes of setaria and pangola hay than the unshorn sheep during the 3 rd -5 th weeks after shearing. At the lower ambient temperature of Expt 2, the increases in hay intake of the shorn sheep were greater, compared with those of the unshorn sheep, than they were in Expt $r$.

4. Shearing was not followed by any consistent changes in the digestibilities of the hays. The differences in the amounts of dry matter digested by the shorn and unshorn sheep were closely related to their dry-matter intakes.

5. It was concluded that the intake of poor-quality hay by sheep could increase in response to an increase in energy expenditure produced by shearing, although this response often occurred 2-3 weeks after shearing. Thus ruminal fill and rate of passage, which are generally considered to control the intake of roughages of low digestibility, may be responsible only for the shortterm control of food intake.

6. The lucerne-fed sheep in both experiments increased their weights and had digestible dry-matter intakes nearly twice as high as the setaria-fed and pangola-fed sheep. The decreased intakes of lucerne hay of the shorn sheep suggested that some mechanism, other than one regulating energy balance, was controlling intake in these experiments.

The long-term control of food intake in the adult monogastric animal is believed to be maintained by mechanisms which balance energy intake against energy expenditure so that the reserve of energy (as fat) is maintained (Kennedy, I96r). Numerous experiments have been conducted on the factors controlling food intake in the ruminant, and in these experiments, variation in energy expenditure has necessarily been minimized. For instance, in a study of the hay intake of sheep in metabolism crates Blaxter, Wainman \& Wilson (I96r) found that the intake of food was closely related to its apparent digestibility. This general effect was also observed when sixty-

* Present Address: National Institute for Research in Dairying, Shinfield, Reading, Berkshire, RG2 9 AT. 
three frozen grasses, ranging in organic-matter digestibility from 58 to $85 \%$, were fed to sheep (Minson, Harris, Raymond \& Milford, I964). Conrad, Pratt \& Hibbs (1964) gave lactating cows diets whose dry-matter digestibility ranged from 52 to $80 \%$ and concluded that, when the dry-matter digestibility was greater than about $67 \%$, the primary determinant of food intake was the physiological state of the animal, but when the digestibility was less than $67 \%$ intake was controlled by the size of the animal and by the digestibility and rate of passage of the food.

Differences in energy expenditure have also been shown to affect the food intake of ruminants. Hutton ( $\mathrm{I}^{6} 6_{3}$ ) observed that lactating cows ate $52 \%$ more food than dry cows, and Campling (1966) reported that lactating cows consumed $29 \%$ more goodquality hay or $8 \%$ more concentrate than their dry non-pregnant monozygotic twins. When sheep are shorn, their intake of food increases (Wheeler, Reardon \& Lambourne, 1963; Wodzicka-Tomaszewska, 1963; Webster \& Lynch, I966). These increases were

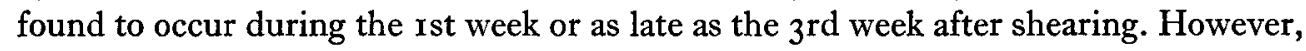
in all these studies good-quality food was offered, so that the results are not inconsistent with the hypothesis of Conrad et al. (1964). If that hypothesis is generally applicable then any increase in energy expenditure of ruminants offered only foods of low digestibility should not lead to any increase in food intake since the intake of these foods is limited by their high content of indigestible material rather than by the physiological requirements of the animal.

To examine this hypothesis, two experiments were conducted in which the energy expenditure of sheep offered three qualities of hay was increased by shearing, and the intakes and apparent dry-matter digestibilities of the hays were measured. The experiments were conducted during two seasons of the year between which the mean ambient temperatures differed by $\mathrm{I} 2^{\circ}$.

\section{EXPERIMENTAL}

Foods

Three hays were used in each experiment. The low-quality hay was made from a mature stand of pangola grass (Digitaria decumbens), the medium-quality from a 2-month regrowth of Setaria sphacelata, and the high-quality foods were two lucerne (Medicago sativa) hays. All the hays were produced from pastures growing on fertile alluvial soils.

Each hay was mixed, chopped and weighed into sacks. Samples were analysed for dry matter in an oven at $100^{\circ}$ for $16 \mathrm{~h}$, for nitrogen by Kjeldahl digestion using a selenium catalyst (McKenzie \& Wallace, 1954) and for ash by heating for $16 \mathrm{~h}$ at $55^{\circ}$.

\section{Animals}

In Expt I, sixty wethers (mean weight before shearing $40.8 \mathrm{~kg}$ ) carrying 8 months' wool and accustomed to intake and digestibility experiments were used. They were weighed, divided into six groups of similar mean weight and placed in metabolism crates in a brick building (Minson \& Milford, I968) at the Cooper Laboratory on I I March 1968. 
Each of the three hays was offered ad lib., using the feeding procedures previously described by Minson ( 1967 ), to two groups of ten wethers for a $7 \mathrm{~d}$ preliminary period before shearing. One of the two groups of wethers given each hay was shorn, and all the sheep were then fitted with harness and faeces collection bags. Dry-matter intakes and digestibilities were determined during the following 5 weeks in five $7 \mathrm{~d}$ measurement periods. The results for the Ist week after shearing include the period of $6 \mathrm{~h}$ when the sheep were being shorn, during which food was withheld and faeces were not collected.

Expt 2 was conducted similarly except that fifty-two wethers (mean weight before shearing $44.5 \mathrm{~kg}$ ) were used, twenty being assigned to the lucerne treatment, sixteen to the setaria and sixteen to pangola. The experiment began on 25 June 1968 . Of these sheep, half had been shorn in Expt $\mathrm{I}$ and had 4 months of regrowth of wool while the remainder had 12 months regrowth. Sheep with long or medium-length wool were equally divided among the hay treatments and between the shearing groups within each treatment. The lengths of wool recorded at four sites over the shoulder and rib of each sheep the day after the shearing day, were $130,43.2$ and $4.5 \mathrm{~mm}$ for the sheep with long and medium wool and for the shorn sheep respectively.

\section{Temperatures}

The temperature of the brick building which housed the sheep was continuously recorded during both experiments. In Expt I the mean weekly maximum temperature remained at $30^{\circ}$ for the 5 weeks; the mean weekly minimum temperature decreased from $23^{\circ}$ in the ist week to $18^{\circ}$ in the last week of the experiment. The mean weekly maximum temperature in Expt 2 decreased throughout the experiment from 19 to $16^{\circ}$ and the mean weekly minimum temperature from I I to $5^{\circ}$ in the final week. The mean temperatures in Expts $I$ and 2 were 25 and $13^{\circ}$ respectively.

Table 1. Chemical composition, intake and apparent dry-matter digestibility of three hays fed to unshorn and shorn sheep

\begin{tabular}{|c|c|c|c|c|c|c|c|}
\hline \multirow[b]{3}{*}{ Hay offered } & \multicolumn{3}{|c|}{ Percentage composition } & \multirow{2}{*}{\multicolumn{2}{|c|}{ Intake* $(\mathrm{g})$}} & \multirow{2}{*}{\multicolumn{2}{|c|}{$\begin{array}{c}\text { Apparent } \\
\text { dry-matter } \\
\text { digestibility* }(\%)\end{array}$}} \\
\hline & \multirow{2}{*}{$\underset{\text { matter }}{\text { Dry }}$} & \multirow{2}{*}{$\begin{array}{l}\text { Nitrogen } \\
\text { (g/roo } g \\
\text { DM) }\end{array}$} & \multirow{2}{*}{$\begin{array}{l}\text { Ash } \\
\text { (g/IOO g } \\
\text { DM) }\end{array}$} & & & & \\
\hline & & & & Unshorn & Shorn & Unshorn & Shorn \\
\hline $\begin{array}{l}\text { Expt } x \text { : } \\
\text { Lucerne I } \\
\text { Setaria } \\
\text { Pangola }\end{array}$ & $\begin{array}{l}88 \cdot 0 \\
88 \cdot 5 \\
88 \cdot 9\end{array}$ & $\begin{array}{l}2 \cdot 63 \\
I \cdot 45 \\
0.64\end{array}$ & $\begin{array}{r}9 \cdot 2 \\
11 \cdot 2 \\
9 \cdot 4\end{array}$ & $\begin{array}{r}1260 \pm 18 \cdot 4 \\
682 \pm 10 \cdot 0 \\
727 \pm 16 \cdot 3\end{array}$ & $\begin{array}{r}1082 \pm 26 \cdot 8 \\
689 \pm 13.3 \\
785 \pm 12.5\end{array}$ & $\begin{array}{l}60 \cdot 6 \pm 0.4 \\
54 \cdot 8 \pm 0.4 \\
49 \cdot 4 \pm 1 \cdot 0\end{array}$ & $\begin{array}{l}60.9 \pm 0.4 \\
51.9 \pm 0.6 \\
47.5 \pm 0.5\end{array}$ \\
\hline $\begin{array}{l}\text { Expt 2: } \\
\text { Lucerne } 2 \\
\text { Setaria } \\
\text { Pangola }\end{array}$ & $\begin{array}{l}83 \cdot 6 \\
88 \cdot 5 \\
88 \cdot 9\end{array}$ & $\begin{array}{l}3.37 \\
r .45 \\
0.64\end{array}$ & $\begin{array}{l}10 \cdot 4 \\
11 \cdot 2 \\
9 \cdot 4\end{array}$ & $\begin{array}{r}1439 \pm 17 \cdot 8 \\
695 \pm 17 \cdot 2 \\
775 \pm 16 \cdot 5\end{array}$ & $\begin{array}{r}1458 \pm 32 \cdot 1 \\
826 \pm 22 \cdot 7 \\
892 \pm 19 \cdot 1\end{array}$ & $\begin{array}{l}70 \cdot 6 \pm 0.3 \\
52 \cdot 4 \pm 0.8 \\
46 \cdot 2 \pm 0.8\end{array}$ & $\begin{array}{l}70 \cdot 5 \pm 0.4 \\
50 \cdot 1 \pm 0.8 \\
47.5 \pm 0.8\end{array}$ \\
\hline
\end{tabular}




\section{RESULTS}

In both experiments, the mean intakes of the sheep were higher when given lucerne hay than when given either of the other hays, regardless of whether the sheep were shorn or unshorn (Table I). As the lucerne hay had the highest apparent digestibility, these results are in agreement with the general relationship between intake and digestibility which was noted on p. 32. However, the intakes of setaria hay were always less than those of pangola hay although the setaria hay was considerably more digestible. Considering the 5 -week period after shearing, the shorn sheep ate less lucerne hay than the unshorn sheep in Expt I $(P<0.00 \mathrm{I})$, more setaria hay in Expt 2 $(P<0.00 \mathrm{I})$ and more pangola hay in both experiments $(P<0.01$ and $P<0.00 \mathrm{I}$ respectively).

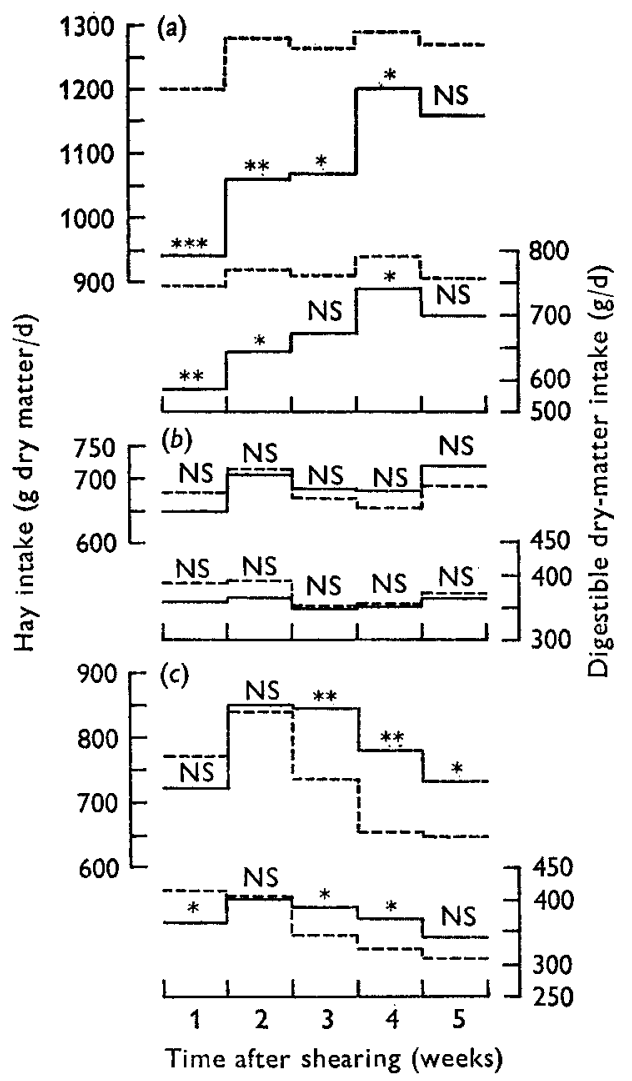

Fig. I

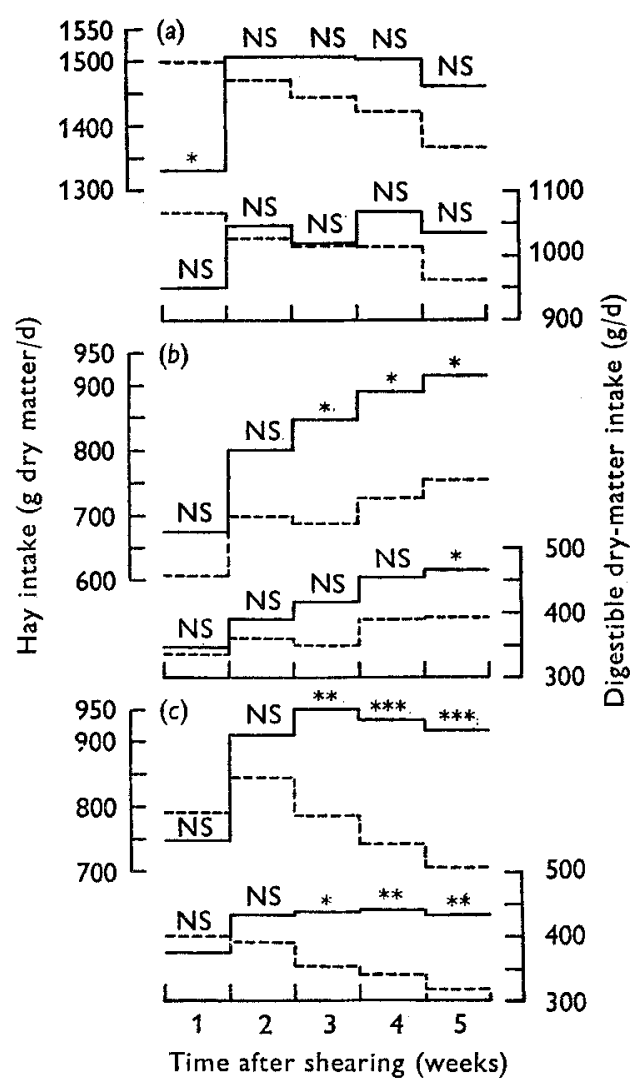

Fig. 2

Fig. I. Expt I. Dry-matter and digestible dry-matter intake of $(a)$ lucerne, $(b)$ setaria and $(c)$ pangola hays by shorn, - , and unshorn, --., sheep. NS, *,**,*** indicate that the mean intakes of the shorn and unshorn sheep were not significantly different, significantly different at the $5, \mathrm{I}$ and $0 . \mathrm{I} \%$ levels respectively. (Mean ambient temperature $25^{\circ}$.)

Fig. 2. Expt 2. Dry-matter and digestible dry-matter intake of (a) lucerne, $(b)$ setaria and $(c)$ pangola hays by shorn, - , and unshorn, ---, sheep. NS, *,**,*** indicate that the mean intakes of the shorn and unshorn sheep were not significantly different, significantly different at the $5, \mathrm{I}$ and $0 . \mathrm{I} \%$ levels respectively. (Mean ambient temperature $13^{\circ}$.) 
Shearing had a negligible effect upon the dry-matter digestibility of lucerne hay in either experiment but led to significant reductions in the digestibilities of setaria in both experiments and of pangola hay in $\operatorname{Expt} \mathrm{I}(P<0.05)$. The greatest reduction in the digestibility of any hay, associated with shearing, was observed with setaria hay in Expt I where there was no difference in the intakes of the shorn and unshorn sheep.

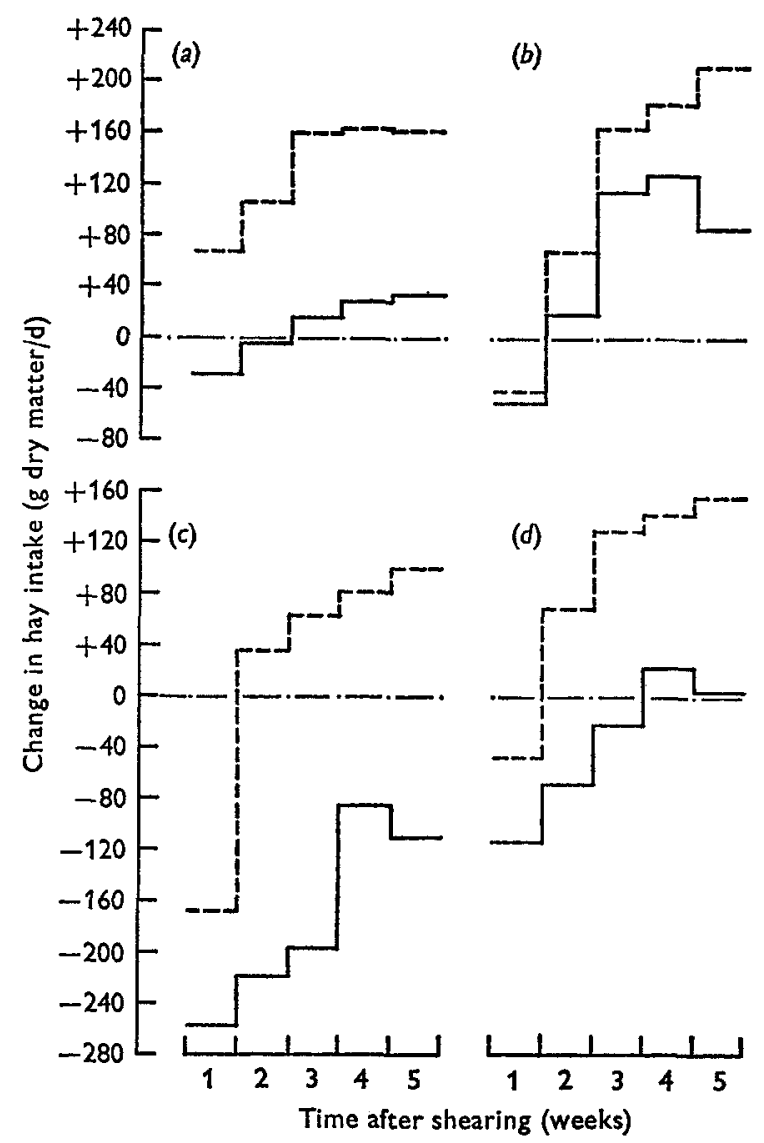

Fig. 3. Effect of ambient temperature on the change in hay intake of sheep after shearing. -, Expt $x$ at $25^{\circ} ;-\cdots$, Expt 2 at $13^{\circ} ;-$ - - intake of unshorn sheep; $(a)$, setaria hay; $(b)$, pangola hay; $(c)$ two lucerne hays; $(d)$, mean for the three hays.

The differences between the food intakes of the shorn and unshorn sheep were not consistent over the 5-week period after shearing. In both experiments, the food intake of the shorn group receiving the lucerne was significantly lower than that of the unshorn group in the week following shearing (Figs. I, 2). This depression in intake was greater in Expt I than in Expt 2; it lasted for 5 weeks in Expt r, but occurred only in the Ist week after shearing in Expt 2. These differences may have resulted partly from the $12^{\circ}$ difference in ambient temperature and partly from the difference in the lucerne hays given in the two experiments. 
The intakes of setaria in Expt I were similar for both the shorn and unshorn groups, but in Expt 2 the intake of the shorn sheep was higher than that of the unshorn sheep, although the differences were significant only after the and week after shearing.

In both experiments the intake of pangola hay by the shorn sheep was depressed in the Ist week after shearing, and when the results from the two experiments were pooled this effect became significant $(P<0.05)$. Two weeks later, the shorn sheep had significantly higher intakes of pangola hay than the unshorn sheep.

Table 2. Expt 2. Effect of the length of wool before shearing upon the mean intake of hay in shorn and unshorn sheep

\begin{tabular}{|c|c|c|c|c|c|c|c|c|}
\hline \multirow{2}{*}{$\begin{array}{l}\text { Food } \\
\text { offered }\end{array}$} & \multirow{2}{*}{$\begin{array}{l}\text { Shorn } \\
\text { or } \\
\text { unshorn }\end{array}$} & \multirow{2}{*}{$\begin{array}{c}\text { Mean } \\
\text { length } \\
\text { of wool } \\
\text { before } \\
\text { shearing } \\
(\mathrm{mm})\end{array}$} & \multirow{2}{*}{$\begin{array}{l}\text { No. of } \\
\text { sheep }\end{array}$} & \multicolumn{5}{|c|}{ Intake of hay after shearing $(\mathrm{g} / \mathrm{d})$} \\
\hline & & & & Week I & Week 2 & Week 3 & Week 4 & Week 5 \\
\hline Lucerne & $\begin{array}{l}\text { Unshorn } \\
\text { Shorn } \\
\text { Shorn }\end{array}$ & $\begin{array}{r}\overline{43} \\
\text { r30 }\end{array}$ & $\begin{array}{r}\text { I0 } \\
5 \\
5\end{array}$ & $\begin{array}{l}1497 \\
1287^{*} \\
1370\end{array}$ & $\begin{array}{l}1471 \\
1561 \\
1436\end{array}$ & $\begin{array}{l}1443 \\
1610^{*} \\
1378\end{array}$ & $\begin{array}{l}\text { I421 } \\
\text { I618* } \\
\text { I } 357\end{array}$ & $\begin{array}{l}\text { I } 364 \\
\text { I } 568^{*} \\
\text { I356 }\end{array}$ \\
\hline $\begin{array}{l}\text { Setaria } \\
\text { and } \\
\text { pangola }\end{array}$ & $\begin{array}{l}\text { Unshorn } \\
\text { Shorn } \\
\text { Shorn }\end{array}$ & $\begin{array}{r}\overline{43} \\
13{ }^{\circ}\end{array}$ & $\begin{array}{r}\text { r6 } \\
8 \\
8\end{array}$ & $\begin{array}{l}700 \\
692 \\
731\end{array}$ & $\begin{array}{l}773 \\
802 \\
913^{*}\end{array}$ & $\begin{array}{l}73^{8} \\
817 \\
980^{* * *}\end{array}$ & $\begin{array}{l}734 \\
839 * * \\
984^{* * * *}\end{array}$ & $\begin{array}{c}73 \mathrm{I} \\
859^{* * *} \\
974^{* * * *}\end{array}$ \\
\hline
\end{tabular}

Intake of shorn sheep significantly different from that of unshorn sheep: * $P<0.05$, ** $P<0.01$, *** $P<0.001$.

The mean differences in the intake of hay between the shorn and unshorn sheep on the three diets for each of the 5 weeks (Fig. 3 ) show differences between the hays in the two experiments which may have been due to differences in the environmental temperature. In Expt I, when the mean ambient temperature was $25^{\circ}$, the shorn sheep ate, on average, $7 \mathrm{~g} / \mathrm{d}$ more setaria hay than the unshorn sheep during the 5 -week experimental period; in Expt 2, when the ambient ten perature was $13^{\circ}$, the shorn sheep ate, on average, $13 \circ \mathrm{g} / \mathrm{d}$ more of the same setaria hay. Corresponding values for pangola hay were $+5^{8}$ and $+\mathrm{II}_{5} \mathrm{~g} / \mathrm{d}$. The lucerne hays given in the two experiments were different, so that the results are not truly comparable, but the corresponding values are $-174 \mathrm{~g} / \mathrm{d}$ and $+22 \mathrm{~g} / \mathrm{d}$. Thus the $12^{\circ}$ lower temperature in Expt 2 resulted in a more positive response to shearing, the differences in intake being 123,57 and $196 \mathrm{~g} / \mathrm{d}$ for setaria, pangola and the lucerne hays respectively.

Although there were differences in the apparent digestibilities of the hays, the differences in the amount of dry matter digested each week by the shorn and unshorn sheep mirrored the changes in the dry-matter intake (Figs. I, 2).

In Expt 2, it was possible to study the effect of the length of wool before shearing on the changes in food intake resulting from shearing. Because of the smaller number of sheep in the setaria and pangola treatments in Expt 2, the results from these treatments were pooled. The mean intakes are shown in Table 2. With the sheep given lucerne, although the numbers of sheep involved were small, those sheep which had $43 \mathrm{~mm}$ of wool before shearing had a significantly depressed intake during the rst 
week after shearing and then had a significantly increased intake in the $3^{\text {rd, }} 4^{\text {th }}$ and $5^{\text {th }}$ weeks after shearing. The intake of the formerly long-wooled sheep was less, though not significantly so, than that of the unshorn sheep for the whole experimental period. On the other hand, the results for the setaria-pangola treatments indicated that the food intake of the formerly long-wooled sheep increased at an earlier time and to a more marked extent than that of the sheep that formerly had medium-length wool.

During the 5 weeks after shearing the changes in weight were similar for both the shorn and unshorn sheep (Table 3) despite the large differences in intake of hay. Sheep offered lucerne gained weight while those offered setaria or pangola lost weight.

\section{Table 3. Mean weight changes $(\mathrm{kg})$ of the sheep during the 5-week experimental period}

\begin{tabular}{|c|c|c|c|}
\hline \multicolumn{2}{|c|}{ Food offered } & Shorn* & Unshorn \\
\hline Lucerne: & $\begin{array}{l}\text { Expt I } \\
\text { Expt } 2\end{array}$ & $\begin{array}{l}+3.0 \\
+3.2\end{array}$ & $\begin{array}{l}+3.5 \\
+3.9\end{array}$ \\
\hline Setaria: & $\begin{array}{l}\text { Expt I } \\
\text { Expt } 2\end{array}$ & $\begin{array}{l}-6 \cdot 6 \\
-2 \cdot 6\end{array}$ & $\begin{array}{l}-5.3 \\
-1.6\end{array}$ \\
\hline Pangola: & $\begin{array}{l}\text { Expt I } \\
\text { Expt } 2\end{array}$ & $\begin{array}{r}-8.5 \\
0.0\end{array}$ & $\begin{array}{l}-8.3 \\
+0.3\end{array}$ \\
\hline & & Mean & $-1 \cdot 3$ \\
\hline
\end{tabular}

* Corrected for the weight of fleece removed.

\section{DISCUSSION}

The object of this work was to test the hypothesis of Conrad et al. (1964) that the size of the animal and the digestibility of the food were the major factors controlling food intake when the dry-matter digestibility of the food was lower than $67 \%$. The results reported in this paper indicate that changes in the energy requirements of sheep caused by shearing can increase the voluntary intake of poor-quality foods, as has been previously demonstrated for high-quality foods. The changes in voluntary intake after shearing were also related to the ambient temperature and quality of the food. The larger increases in intake occurred at the lower temperature, when the energy requirements of the shorn sheep would be increased, and with the food of poorer quality. Thus the energy requirement of the sheep can affect its voluntary intake of foods of low digestibility, and hence digestibility and rate of passage are not the only factors controlling voluntary intake of poor-quality foods.

During these experiments no measurements were made of the energy expenditure of the sheep. However Blaxter, Graham \& Wainman (1959) have shown that unshorn sheep have wide thermoneutral zones when given $1200 \mathrm{~g}$ dried grass/d but that the minimum critical temperatures of the same sheep after close-clipping were $39^{\circ}, 33^{\circ}$ and $24-27^{\circ}$ when given 600,1200 and $1800 \mathrm{~g}$, respectively, of dried grass daily (Graham, Wainman, Blaxter \& Armstrong, 1959). Since the shorn sheep in all the treatments here were observed to shiver in the early mornings during the first 2 weeks following shearing when the mean temperature was $21^{\circ}$ in Expt $\mathrm{I}$ and $10^{\circ}$ in Expt 2, it may be concluded that shearing increased the energy expenditure of the sheep in 
both experiments. The energy necessary for this increased heat production would probably be produced by the mobilization of the fat reserves of the sheep (Graham et al. 1959) and this mechanism would continue to operate until either the energy expenditure decreased following wool growth or the intake of digestible energy was increased by a rise in the voluntary intake of food.

The cause of the initial depression of intake is unknown, but similar effects have been reported by Weiss (1958) and Sykes \& Slee (1969). Weiss subjected rats daily to short acute exposures of cold and suggested that the initial depression of the food intake (lasting $3 \mathrm{~d}$ ) was due to the rats being uncomfortable. As in the present experiments, the depression in food intake recorded by Weiss was only a temporary phenomenon, since 7-24 $\mathrm{d}$ after the beginning of exposure to cold the food intake of the rats was increased when compared with the controls. When Sykes \& Slee (1969) exposed sheep to a temperature of $8^{\circ}$, there was a depression in the intake of those on a high plane of nutrition but not of those on a lower plane of nutrition. Thus, while the suggestion that discomfort limits food intake may be true, the nature of the discomfort is hard to envisage since the sheep on the lucerne treatments, which showed the largest depressions of intake after shearing, were observed to shiver less frequently than the sheep receiving pangola or setaria.

The mean changes in weight of the shorn and unshorn sheep given each hay in both experiments were very similar. In both experiments, the sheep given lucerne gained $3 \mathrm{~kg}$ or more in the 5 -week period, suggesting a positive energy balance, whilst the sheep given pangola and setaria barely maintained or lost weight. The digestible dry-matter intakes of sheep receiving lucerne hay were nearly twice as high as those of the sheep receiving setaria or pangola. In Expt $I$, the shorn sheep given lucerne continued to have lower intakes than the unshorn sheep for the whole 5 weeks after shearing, and in Expt 2 the sheep which had $130 \mathrm{~mm}$ of wool before shearing and were given lucerne also had lower intakes than the unshorn sheep for the same 5-week period. These continued depressions in the intake of lucerne hay of the shorn sheep are almost completely opposed to the results observed when sheep were given setaria or pangola hays. The reasons for these continued depressions of hay intake are not clear. It can only be suggested that when the food intake is greatly in excess of the maintenance requirements of the sheep, a mechanism other than one maintaining an energy balance limits food intake.

Although increased energy expenditure of the sheep must have occurred almost immediately after shearing, a significant rise in hay intake did not occur for at least I week after shearing and in five of the six comparisons there was a decrease in food intake after shearing for at least $\mathbf{I}$ week. Thus the increase in food intake following shearing is not likely to be of any assistance to newly shorn sheep exposed to adverse weather conditions.

The authors thank Mr G. A. Taylor for his care of the sheep and Mr M. N. McLeod for the chemical analysis. 


\section{REFERENCES}

Blaxter, K. L., Graham, N. McC. \& Wainman, F. W. (1959). F. agric. Sci., Camb. 52, 41.

Blaxter, K. L., Wainman, F. W. \& Wilson, R. S. (I96r). Anim. Prod. 3, 5 I.

Campling, R. C. (1966). Br. F. Nutr. 20, 25.

Conrad, H. R., Pratt, A. D. \& Hibbs, J. W. (r964). F. Dairy Sci. 47, 54.

Graham, N. McC., Wainman, F. W., Blaxter, K. L. \& Armstrong, D. G. (1959). F. agric. Sci., Camb. $\mathbf{5 2}, \mathbf{I}_{3}$.

Hutton, J. B. (1963). Proc. N. Z. Soc. Anim. Prod. 23, 39.

Kennedy, G. C. (I96I). Proc. Nutr. Sac. 20, 58.

McKenzie, H. A. \& Wallace, H. S. (1954). Aust f. Chem. 7, 55.

Minson, D. J. (1967). Br. $\mathscr{~}$. Nutr. 21, 587.

Minson, D. J., Harris, C. E., Raymond, W. F. \& Milford, R. (1964). F. Br. Grassld Soc. I9, 298.

Minson, D. J. \& Milford, R. (1968). F. agric. Sci., Camb. 71, $3^{81 .}$

Sykes, A. R. \& Slee, J. (1969). Anim. Prod. I1, 65.

Webster, M. E. D. \& Lynch, J. J. (1966). Proc. Aust. Soc. Anim. Prod. 6, 234.

Weiss, B. (1958). Science, N.Y. 127, 467.

Wheeler, J. L., Reardon, T. F. \& Lambourne, L. J. (1963). Aust. F. agric. Res. 14, 364.

Wodzicka-Tomaszewska, M. (1963). N.Z. Fl agric. Res. 6, 440. 